\title{
BACILLARY DYSENTERY IN CYPRUS
}

\author{
Captain R. N. MILES, M.B., B.S., R.A.M.C. \\ British Military Hospital, Rinteln
}

SUMMARY: An outbreak of 88 proven cases of shigella dysentery occurred in the Eastern Sovereign Base Area of Cyprus. The pattern of the epidemic would suggest fly borne transmission with person to person contact playing little part. A therapeutic trial of ampicillin was undertaken and there was no significant alteration in the duration of symptoms or the clearance of pathogens from the stools.

An outbreak of shigellosis occurred in Autumn 1974 amongst service personnel in the Eastern Sovereign Base Area of Cyprus. The clinical aspects, epidemiology and an antibiotic trial are described.

\section{Clinical features}

Eighty-eight cases of shigellosis were admitted to the British Military Hospital in Dhekelia over the course of two months. Several other cases of diarrhoea were admitted from whom no pathogens were isolated.

The severity of the illness varied from a few loose stools to the passage of bloody fluid up to fifty times per day. Other symptoms included fever, nausea, occasional vomiting and abdominal cramps. There was no obvious relationship between the severity of the symptoms and the organism isolated. Abdominal tenderness was a common physical sign. Prostration and dehydration were surprisingly infrequent considering the high environmental temperatures and intravenous rehydration was required for only five patients. This is probably explained by early hospital admission.

Fluids only were given until the diarrhoea began to settle. Alternate cases received $0.5 \mathrm{~g}$ of ampicillin four times daily regardless of the severity of the symptoms. Ampicillin was received by 22 patients and 39 received no antibiotic.

The disparity in the figures is explained by the several cases of diarrhoea not proven to be dysenteric which were subsequently excluded from the trial.

The average duration of diarrhoea was 5 days with a range of 1-15 days in both groups. At the end of one week 33 ( 85 per cent) of the untreated and 18 ( 82 per cent) of the treated were symptom free. Stools or rectal swabs were cultured daily and the infection considered to be eradicated when three consecutive cultures were negative for pathogens. The limitations of this method are obvious as relapse and the development of a prolonged carrier state have been frequently described. However, repeat stool cultures one month after the three "clear" stools were negative in all cases.

The average duration from the onset of symptoms to the third pathogen-free stool was 10.4 days (range 5-23 days) in the untreated group and 8.6 days (range 4-14 days) in the group receiving ampicillin. At the end of one week 24 (60 per cent) of the untreated and 16 ( 73 per cent) of the treated were clear of pathogens and at the end of two weeks 35 ( 90 per cent) of the untreated and all of those given ampicillin were free from infection. These results are not statistically significant $(P=0.3)$. 
There were few complications. Four patients developed a large joint polyarthropathy beginning 7-20 days after the onset of dysentery. The isolated pathogens were Shigella sonnei in three instances and Shigella flexneri Type VI in one. Joint symptoms persisted for 2-6 weeks. All laboratory investigations were normal apart from an increased E.S.R. A sterile conjunctivitis and an anterior uveitis developed in two individuals two weeks after the onset of dysentery. There were two cases of moderately severe disaccharide intolerance, which prolonged the diarrhoea after eradication of infection, in a 30 day old infant and a soldier aged 20 years.

\section{Bacteriology}

Stool culture was performed in the laboratory at the British Military Hospital, Dhekelia and subtyping at the Salmonella and Shigella Reference Laboratory, Colindale. The following types were isolated (Table I).

Table I

Shigella subtypes isolated

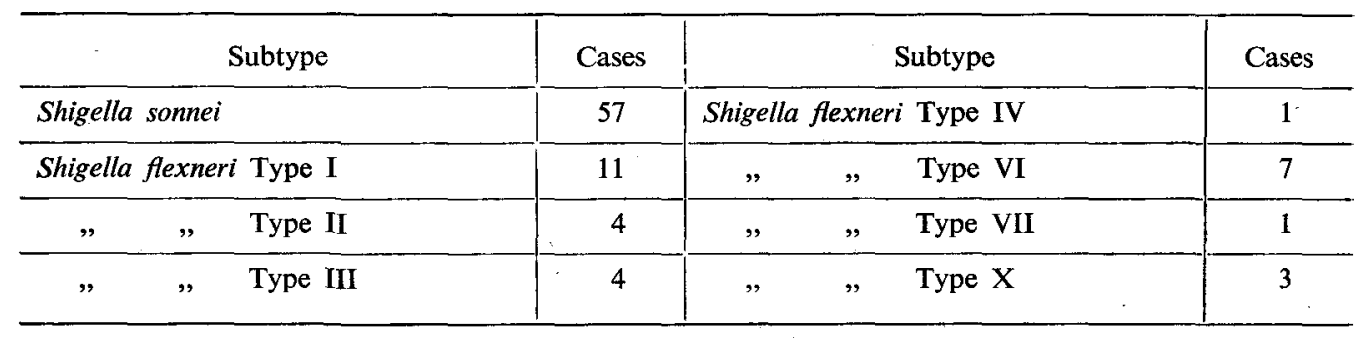

Antibiograms performed at Colindale revealed that all organisms were sensitive to ampicillin, neomycin, tetracycline and trimethoprim and all but the Shigella flexneri Type III were resistant to streptomycin and sulphathiazole.

\section{Epidemiology}

The epidemic was a consequence of the recent Cyprus war. Approximately 20,000 refugees crowded in and around the Sovereign Base Area. Camps were set up to accommodate them and water supply and field sanitation instituted. Central cookhouses were erected under military supervision and an education programme on camp hygiene was promulgated. However it was not possible to persuade all refugees to live in the camps and many family groups camped and moved randomely around the area. It takes time for a civilian population to adapt to field conditions and hygiene was initially poor at a time when the fly population was maximal. Bacillary dysentery occurred in the camps but was treated by refugee doctors without referral to the British Military Hospital and no statistics are available.

Despite stringent hygiene measures amongst the military population of the Sovereign Base Area every unit suffered a few cases of shigellosis. The geographical pattern of the epidemic indicated fly borne transmission. Person to person contact is also a major method of infection and it is a measure of the success of the hygiene campaign mounted at the beginning of the refugee situation that only 8 cases occurred in the schools and in only 6 families was more than one member proven to be affected. 
As the civilian refugees learned camp hygiene and the wandering of family groups diminished the epidemic began to subside. It ended two months after the onset aided by the change of season and attenuation of the fly population.

\section{Discussion}

Opinions on the use of antibiotics in the treatment of shigellosis have varied over the years. Sulphonamides were widely prescribed in the 1939-45 war (Hardy and Watt 1944) and their value confirmed by Long (1950) and Boyd (1950). Cheever (1952) reported resistance and gave the opinion that terramycin, aureomycin and chloramphenicol were the drugs of choice. Since 1960 ampicillin had enjoyed favour and several studies have shown the drug will decrease the excretion of shigellae in the stools and abbreviate the clinical course of both mild and severe disease (Haltalin et al 1967 and Haltalin et al 1972). Heyworth, however, in 1970 tested several antibiotics and found there was no difference in the clearance rate between treated and control groups. Rapidly increasing resistance to ampicillin has been reported from America (Ross 1972) and England (Davies (1970) and in a recent communication Haltalin (1973) has confirmed this and states that "ampicillin is less useful than formerly thought". Ross (1972) has found that many of the ampicillin resistant strains were multiresistant to three or more antibiotics and suggested that $\mathrm{R}$-factor was responsible.

The pathogenicity of the shigella group appears to have declined over the years. The majority of cases are self limiting fairly mild illnesses in which bacteriological clearance of the stool occurs in 60 per cent of untreated patients within a week. The present weight of evidence, as reviewed by Weissman, Gangarosa and Dupont (1973), would suggest that in view of the rapidity in which multiresistant strains appear and the relative mildness of the disease antibiotics should not be given routinely. This small study would support this view.

\section{Acknowledgements}

I thank Dr. B. Rowe, Director of the Salmonella and Shigella Reference Laboratory, for kindly undertaking the subtyping and antibiograms. I would also like to thank Lieutenant-Colonel A. J. Spicer, Consultant Physician at the British Military Hospital, Dhekelia, for help and encouragement in preparing this paper.

\section{REFERENCES}

BoYD, J. S. K. (1950). Fifty years of tropical medicine. Brit. med. J. i, 37.

Cheever, F. S. (1952). Treatment of shigellosis with antibiotics. Ann. N. Y. Acad. Sci. 55, 1063.

LoNG, P. H. (1950). The clinical use of antibiotics: IV. Treatment of infectious processes. U.S. armed Forces med. J. 1, 1273.

Haltalin, K. C., Nelson, J. D., Ring, R., Sladoje, M. and Hinton, L. V. (1967). Double blind treatment study of shigellosis. J. Pediat. 70,970-981.

Haltalin, K. C., Kusmeisz, H. T., Hinton, L. V. and Nelson, J. D. (1972). Treatment of acute diarrhoea in outpatients. Amer. J. Dis. Child. 124, 554-561.

Haltalin, K. C. (1973). Letter to the Editor. Amer. J. Dis. Child. 125, 458.

Hardy, A. V. and WatT, J. (1944). The acute diarrhoeal diseases. J. Amer. med. Ass. 124, 1173.

HEYworTH, B. (1970). Colistin and other antibiotics in the treatment of specific gastrointestinal infections. Med. Offr. 123, 349.

Weissman, J. B., Gangaroso, E. J. and Dupont, H. L. (1973). J. infect. Dis. 127, 611-613. 